\title{
Audible thunder characteristic and the relation between peak frequency and lightning parameters
}

\author{
OuYang Yuhua ${ }^{1,2}$ and Yuan Ping ${ }^{1, *}$ \\ ${ }^{1}$ College of Physics and Electronic Engineering, Northwest Normal University, Lanzhou 730 070, China. \\ ${ }^{2}$ School of Mathematics, Physics and Software Engineering, Lanzhou Jiaotong University, Lanzhou 730 070, China. \\ ${ }^{*}$ Corresponding author.e-mail: ouyangyh1104@163.com
}

In recent summers, some natural lightning optical spectra and audible thunder signals were observed. Twelve events on 15 August 2008 are selected as samples since some synchronizing information about them are obtained, such as lightning optical spectra, surface E-field changes, etc. By using digital filter and Fourier transform, thunder frequency spectra in observation location have been calculated. Then the two main propagation effects, finite amplitude propagation and attenuation by air, are calculated. Upon that we take the test thunder frequency spectra and work backward to recalculate the original frequency spectra near generation location. Thunder frequency spectra and the frequency distribution varying with distance are researched. According to the theories on plasma, the channel temperature and electron density are further calculated by transition parameters of lines in lightning optical spectra. Pressure and the average ionization degree of each discharge channel are obtained by using Saha equations, charge conservation equations and particle conservation equations. Moreover, the relationship between the peak frequency of each thunder and channel parameters of the lightning is studied.

\section{Introduction}

Thunder is the acoustic radiation associated with lightning. It is divided into two categories (Few 1969): (1) audible: acoustic energy that can be heard by humans, 2) infrasonic: acoustic energy that is below the frequency that the human ear can detect, generally a few tens of hertz. Audible thunder is a series of degenerated shock waves produced by the gas dynamic expansion of various portions of the rapidly heated lightning channel, while infrasonic thunder is associated with the sudden contraction of a relatively large volume of thundercloud when lightning rapidly removes the charge from that volume. In this paper, the characteristic of audible thunder is analysed considering that it is related to lightning channel parameters.
Spectrographic studies of lightning return strokes show that this electrical discharge process heats the channel gases to a temperature in the range of 20,000 32,000 K (Orville 1968; OuYang et al 2006). The time-resolved spectra of return strokes (Orville 1968) show the effective temperature dropping from $\sim 30,000$ to $\sim 10,000 \mathrm{~K}$ in a period of $40 \mu \mathrm{s}$, and the pressure of the luminous channel dropping to the atmospheric level in the same time interval. The shock wave has propagated over $0.1 \mathrm{~m}$ during this period.

According to Uman (2001) and Orville (1980), Dufay, Israel and Fries were the first to consider the optical spectrum of lightning as a source of quantitative information about the physical conditions in and around the lightning channel. Until now, spectrum has played an important role in the research of most of the lightning channel

Keywords. Thunder; frequency; temperature; electron-density; pressure; ionizability. 
parameters. However, it is difficult to obtain lightning spectrum because of the very high randomicity of natural lightning, resulting in inadequate data on lightning spectra at present. Thunder signal is another approach towards studying lightning when more thunder properties and the relations between thunder and lightning channel parameters are discovered.

The most comprehensive work on the measured frequency spectrum of thunder has been done by Holmes and Brook (1971). A variety of earlier published data has been reviewed by Uman (2001). Recently, studies about infrasound from lightning are mentioned in references of Assink et al (2008); Pasko (2009) and Farges and Blanc (2010). In this paper, audible thunder signals have been obtained and analysed. Thunder signals can supply complementary information for the study of lightning physics. It has proven to be a valuable source of thunder data. For instance, the mean total acoustic energy radiated by flashes could be calculated if the thunder peak frequency is obtained. In addition, some channel parameters could be analysed from thunder data when the optical spectrum of lightning could not be obtained, such as flashes inside the clouds.

\section{Theory}

\subsection{Thunder propagation theory}

Once generated, acoustic pulses from the lightning channel propagate for long distances through the atmosphere. There are two main propagation effects: finite amplitude propagation and attenuation by air.

\subsubsection{Finite amplitude propagation}

As large amplitude acoustic waves propagate through air, Otterman's theory (1959) predicts that the shape of the wave must evolve with time. A single pulse will evolve to the shape of an $\mathrm{N}$ wave; further propagation of the wave produces a lengthening of this $\mathrm{N}$ wave (Uman et al 1970). The result for the wavelength of the positive pressure pulse at the ground, $L_{\mathrm{g}}$, is given by Few et al (1995).

$$
\begin{aligned}
\frac{2}{3}\left(L_{\mathrm{g}}^{3 / 2}-L_{0}^{3 / 2}\right)= & \frac{\gamma+1}{4 \gamma} R_{0} L_{0}^{1 / 2} \Pi_{0} \\
& \times\left[\ln \left(\frac{H_{0}}{R_{0} \cos \theta}\right)-\frac{H_{0}}{2 H_{\mathrm{g}}}\right],
\end{aligned}
$$

where $L_{0}$ is the initial wavelength of the positive pulse at a distance $R_{0}$ from the source, $\gamma$ is the ratio of specific heats, and

$$
\Pi_{0}=\frac{\delta P_{0}}{P_{0}}
$$

gives the overpressure, $\delta P_{0}$, at ambient pressure $P_{0}$.

Usually, the finite amplitude propagation causes a doubling in the wavelength of the positive pulse within the first kilometer, but beyond this range, the wavelength remains approximately constant (Few et al 1995).

\subsubsection{Attenuation by air}

There are three processes on the molecular scale that attenuate the signal by actual energy dissipation. Viscosity and heat conduction represent the molecular diffusion of wave momentum and wave internal energy from the condensation to the rarefaction parts of the wave. The so-called molecular attenuation results from the transfer of part of the wave energy from the translational motion of molecules to internal molecular vibration energy of the $\mathrm{O}_{2}$ molecules during the condensation part of the wave and back out during the rarefaction part of the wave. The phase lag of the energy transfer relative to the wave causes some of the energy to be retrieved from the $\mathrm{O}_{2}$ and appear at an inappropriate phase; thus it goes into the heat rather than the wave. These three processes can be treated theoretically within a common framework. The amplitude of a plane wave, $\delta A$, at a distance, $x$, from the origin $(x=0)$ is given as follows:

$$
\delta A=\delta A_{0} e^{-\alpha x},
$$

where $\delta A_{0}$ is the wave amplitude at the origin. The coefficient of attenuation, $\alpha$, can be shown as follows:

$$
\alpha=\frac{\omega^{2} \tau}{2 c} .
$$

In equation (3), $\omega$ is the wave angular frequency; $c$ is the speed of sound.

The experimental location is in the Qinghai plateau, where lower humidity is common, $h \approx$ $8 \mathrm{gm}^{-3}$. For air at $20^{\circ} \mathrm{C}$ and $1 \mathrm{~atm}, \tau \approx 6.5 \times 10^{-9} \mathrm{~s}$ is the e-folding time for the molecular process being considered. Under a certain propagation distance and environmental condition, the absorption coefficient increases with frequency (Zhang et al 2010).

\subsection{The calculation of channel parameters relying on lightning spectrum}

\subsubsection{Lightning channel temperature}

Lightning plasma temperature is usually measured by spectroscopic methods. In order to calculate the channel temperature, the following assumptions must be made: (1) lightning channel is optically 
transparent; (2) lightning channel plasma contents with local thermodynamic equilibrium (LTE). Average temperatures are qualitatively analysed from lightning spectra to be about $25,000 \mathrm{~K}$. The temperature estimation justifies the use of the two assumptions. Under these conditions, the intensity of line can be given as follows.

$$
I=h v g A N \mathrm{e}^{-E / k T} / 4 \pi Z,
$$

where $v$ is the frequency of the line, $g, A, Z$ and $E$ are the statistical weight, transition probability, partition function and upper excitation energy of corresponding transition, respectively. $T$ is the temperature. Equation (4) can be changed into

$$
\ln (I \lambda / g A)=-E / k T+b,
$$

where $\lambda$ is the wavelength of line in lightning optical spectrum and $b$ is a constant. So, according to the relative intensities of lines and transition parameters obtained by multi-configuration DiracFock (MCDF) method, temperature in lightning discharge channel can be calculated by using the multiple-line method (OuYang et al 2006).

\subsubsection{Electron density}

Based on LTE, the electron density in lightning channel can be calculated by applying the Saha equation.

$$
\begin{aligned}
n_{e}= & 4.83 \times 10^{15}\left(\frac{I_{a}}{I_{i}}\right) \cdot\left(\frac{g A}{\lambda}\right)_{i} \\
& \times\left(\frac{\lambda}{g A}\right)_{a} \cdot T^{3 / 2} 10^{-5040\left(V+E_{i}-E_{a}\right) / T},
\end{aligned}
$$

where $n_{e}$ is the electron density, $I_{a}$ and $I_{i}$ are the line intensities of atom and ion. $V$ is the ionization energy.

\subsubsection{Channel pressure}

The channel pressure can be obtained by applying Dalton's law,

$$
p=\left(n_{e}+\sum_{i} n_{i}-\frac{1}{24 \pi \lambda_{\mathrm{D}}^{3}}\right) k T,
$$

where $\lambda_{\mathrm{D}}$ is Debye length, and expressed as:

$$
\lambda_{\mathrm{D}}=\left[\frac{e^{2}}{\varepsilon_{0} k} \frac{1}{T}\left(n_{e}+\sum_{i \neq e} Z_{i}^{2} n_{i}\right)\right]^{-1 / 2} .
$$

Once channel temperature $T$ and electron density $n_{e}$ are calculated, respectively from equations (5) and (6), the ion densities of NI, NII, OI and OП can be derived with charge conservation equations and particle conservation equations, then the
Debye length $\lambda_{\mathrm{D}}$ can be calculated from equation (8). Solving $\lambda_{\mathrm{D}}$, one can further obtain channel pressure from equation (7).

\subsubsection{Mean ionization degree}

Since channel plasma is required for the LTE condition, charge distribution in different ionization degrees is due to particle collision. Radiation effects can often be ignored, thus the charge distribution expression can be derived as follows.

$$
\begin{aligned}
\frac{n_{i+1} n_{e}}{n_{i}}= & 2\left(2 \pi m_{e} k T / h^{2}\right)^{3 / 2} \\
& \times \frac{z_{i+1}}{z_{i}} e^{-I_{i} / k T} e^{-\Delta I_{i} / k T},
\end{aligned}
$$

where $n_{i}$ and $n_{i+1}$ are $i$-level-ion density and $i+$ 1-level-ion density, $Z_{i}$ and $Z_{i+1}$ are called $i$ level-ion partition function and $i+1$-level-ion partition function. The quantity $\Delta I_{i}$ is the correct value of the ionization energy by applying Debye Hüchel's theory. Taking the initial values of $\Delta I_{i}$, and $I_{i}$, the methods of iterative algorithm are repeatedly adopted, until the relative correct particle densities are obtained. By solving the above and applying Dalton's law, the mean ionization degrees can be obtained.

\section{Observation and analysis}

In recent summers, natural lightning was observed and some good experimental data was obtained, which was about lightning spectrum and audible thunder. The experiment apparatus consists of a high-speed-scanning-digital camcorder with grating and a microphone. A transmission grating of $600 \mathrm{~mm}$ is placed in front of the object lens. The observed optical spectra have a dispersion of $1.3 \mathrm{~nm}$ in the first order of spectrum.

For the data selected to analyse in this paper, the observation location is in Qinghai plateau, of $37^{\circ} 03^{\prime} 47^{\prime \prime} \mathrm{N}, 101^{\circ} 34^{\prime} 57^{\prime \prime} \mathrm{E}$, and the date is 15 August 2008. The altitude of the observation place is $2820 \mathrm{~m}$. The atmospheric pressure is $75730 \mathrm{~Pa}$, relative humidity is about $70 \%$, and the environment temperature is approximately $20^{\circ} \mathrm{C}$. The duration of thunderstorm is about 30 minutes. Total rainfall is $43 \mathrm{~mm}$. Twelve cases, with good thunder acoustic signal and resolvable lightning optical spectrum, are analysed in this paper.

\subsection{The characteristic of audible thunder frequency}

\subsubsection{Corrected thunder signal}

The acoustic signal is collected and recorded with a microphone. The recorded signal is a time series, 


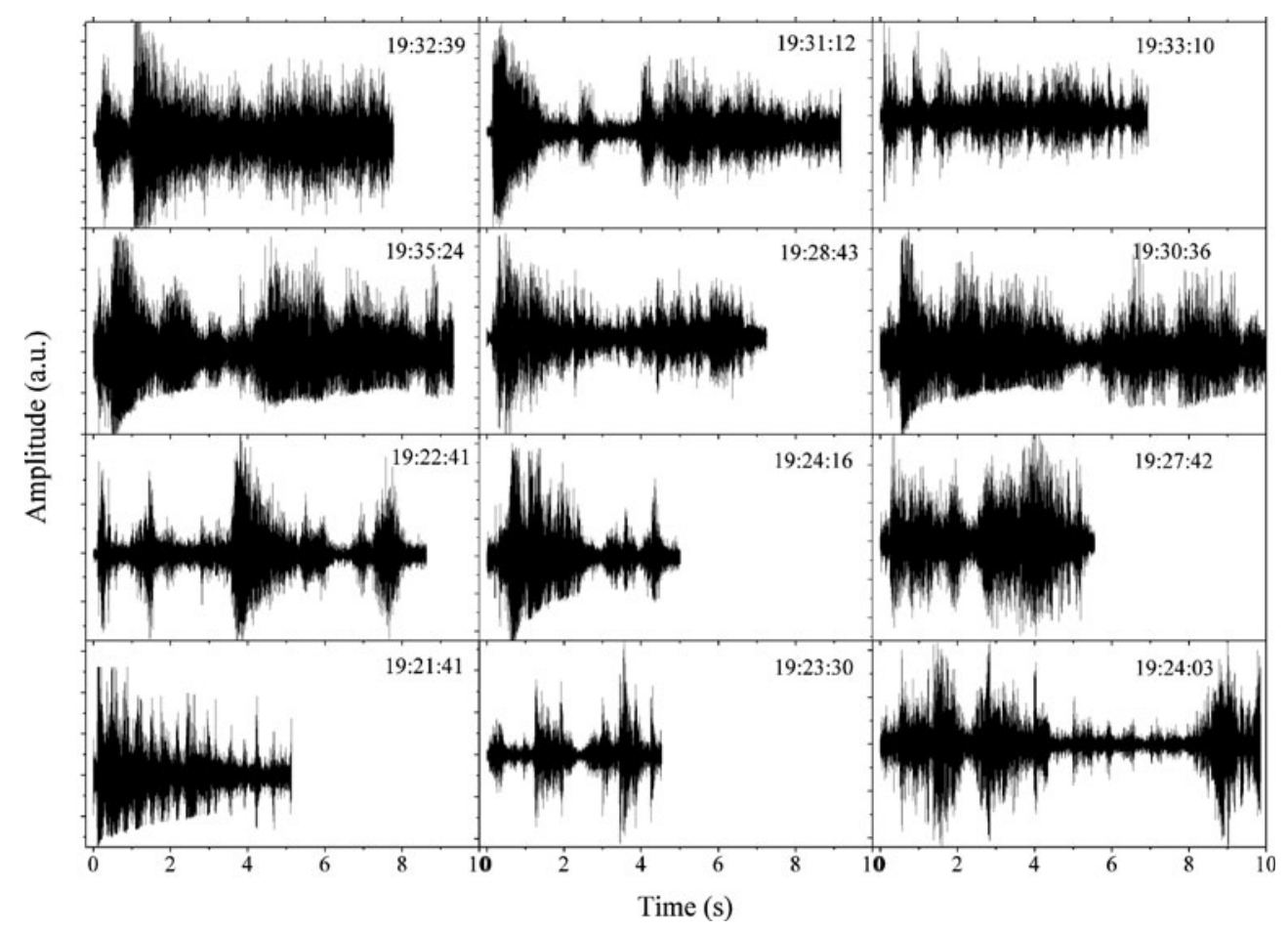

Figure 1. Acoustic signal of the 12 studied thunders, processed by the modern signal processing technique.

interfusing too much environment noise to analyses directly the corresponding performance without pre-processing. Fortunately, the problem can be overcome by employing the modern signal processing technique. Thus, by means of the time domain pre-processing technique such as digital filter, we obtain the time series of thunder signal, which is shown in figure 1 . The 12 thunders shown in figure 1 are sorted following the lightning distance. The thunder name is its relative lightning occurrence time. The propagation distances are from 2 to $7 \mathrm{~km}$. There are usually composed of 3 to 7 claps per flash, and the time interval between claps is typically $1-3 \mathrm{~s}$, where the clap is a sudden loud sound lasting for about $0.2-2 \mathrm{~s}$.

Based on video data obtained by high-speedscanning-digital camcorder, it can been seen that, among the 12 events, there are seven cloud-toground lightnings, and the channel geometries are cylindrical, i.e., 19:21:41, 19:23:30, 19:24:03, 19:24:16, 19:27:42, 19:28:43, and 19:31:12. The rest are cloud-to-cloud lightnings. These cloud-toground lightning channels are nearly straight and vertical. None but 19:21:41 is a simplex return stroke lightning and the thunder has only one clap.

A clap is usually followed by a loud sound which changes in frequency and amplitude and becomes an irregular sound with moderate amplitude, and finally a relatively weak sound of long duration and relative low frequency prior to the next loud clap.

\subsubsection{Thunder frequency spectrum}

The frequency spectra, at the observation site (figure 2a), are calculated from the thunder signals (figure 1) by using numerical discrete-time Fourier transform procedure. Furthermore, the spectra (figure 2b) are calculated at their generation place (the lightning channel) taking into account the two main propagation effects. These graphs are sorted as in figure 1. There is a peak frequency within the range of 210 to $280 \mathrm{~Hz}$ for each of the 12 thunders, which is usually called characteristic peak frequency. In general, thunder has one or more peak frequencies beside the characteristic peak frequency.

Comparing figure 2(b) with figure 2(a), it can be clearly seen that a thunder signal of more than $600 \mathrm{~Hz}$ in the observation location is much weaker than the thunder signal in the generation location for most events. The longer the propagation distance is, more obvious is the attenuation. Furthermore, amplitude of a high frequency zone reduces faster than that of a low frequency zone. In other words, the higher frequency portion of the thunder signal is most strongly affected by propagation. For example, (1) the dominant frequency of 19:24:03 where lightning distance is $7140 \mathrm{~m}$ and is the farthest one, is close to $210 \mathrm{~Hz}$ measured in the observation location; while tracing back to the generation location, the dominant frequency is about $500 \mathrm{~Hz}$, besides the characteristic peak 


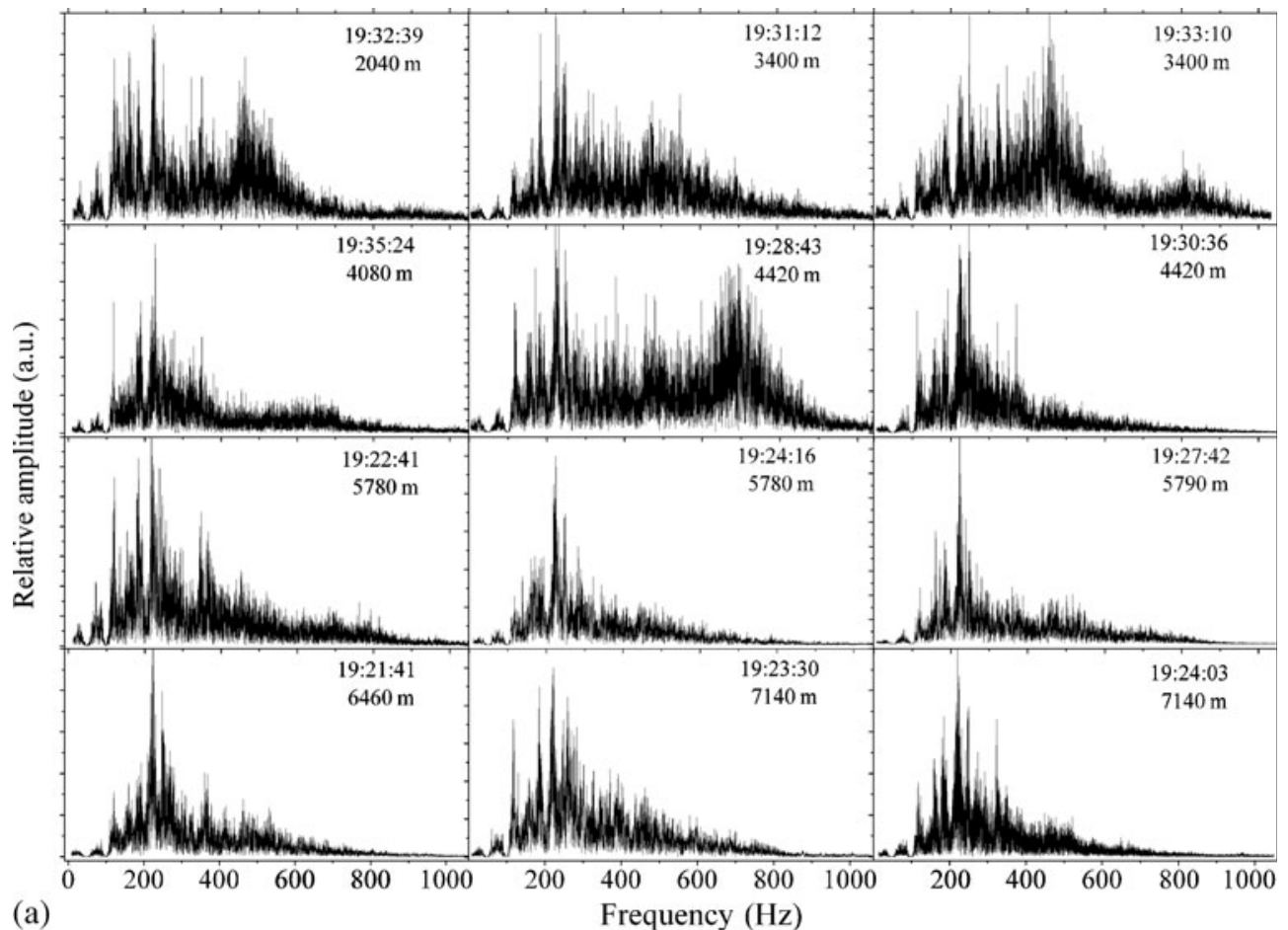

(a)

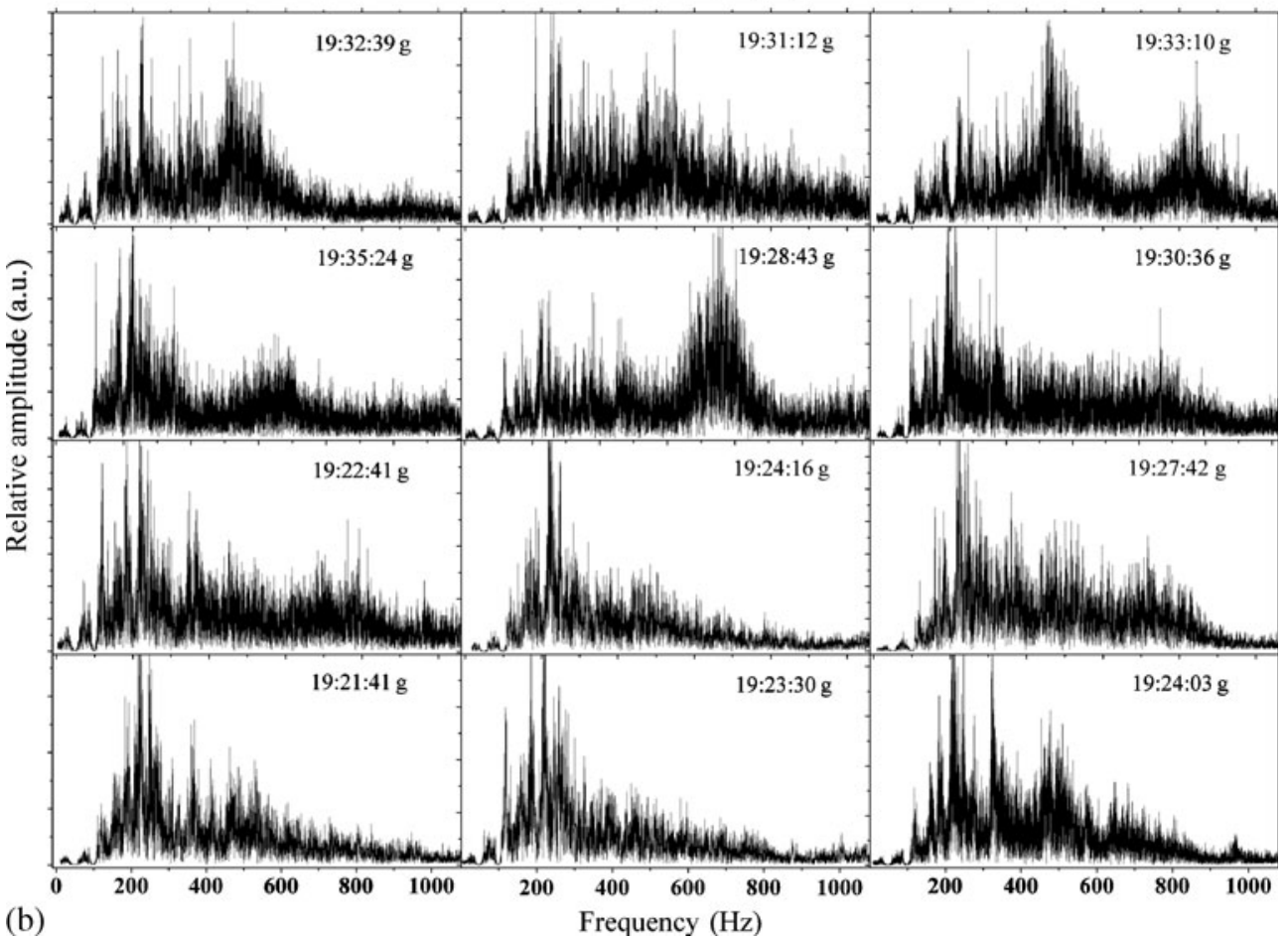

Figure 2. (a) Frequency spectra of thunder at the observation location, before considering the propagation effects. Usually, there are one or several peak frequencies on a given thunder frequency spectrum. Only the characteristic peak frequency is relatively intense for each event of the 12 thunders at the observation site. (b) Frequency spectra of thunder traced to generation location. Comparing with figure 2(a), the attenuation of signal below $160 \mathrm{~Hz}$ is negligible, and the amplitude change increases with frequency.

frequency changes from $210-240 \mathrm{~Hz} ;(2)$ the lightning distance of 19:28:43 is $4420 \mathrm{~m}$, in observation and generation locations, its dominant frequency is respectively, 680 and $750 \mathrm{~Hz}$; moreover, the peak frequency $(750 \mathrm{~Hz})$ in its generation frequency spectrum is more obviously intense than its characteristic peak frequency $(250 \mathrm{~Hz})$. There is little attenuation for frequencies below about $200 \mathrm{~Hz}$. Bass and Losely (1975) calculated that, for $50 \%$ humidity at $20^{\circ} \mathrm{C}$ and a range of $5 \mathrm{~km}$, 


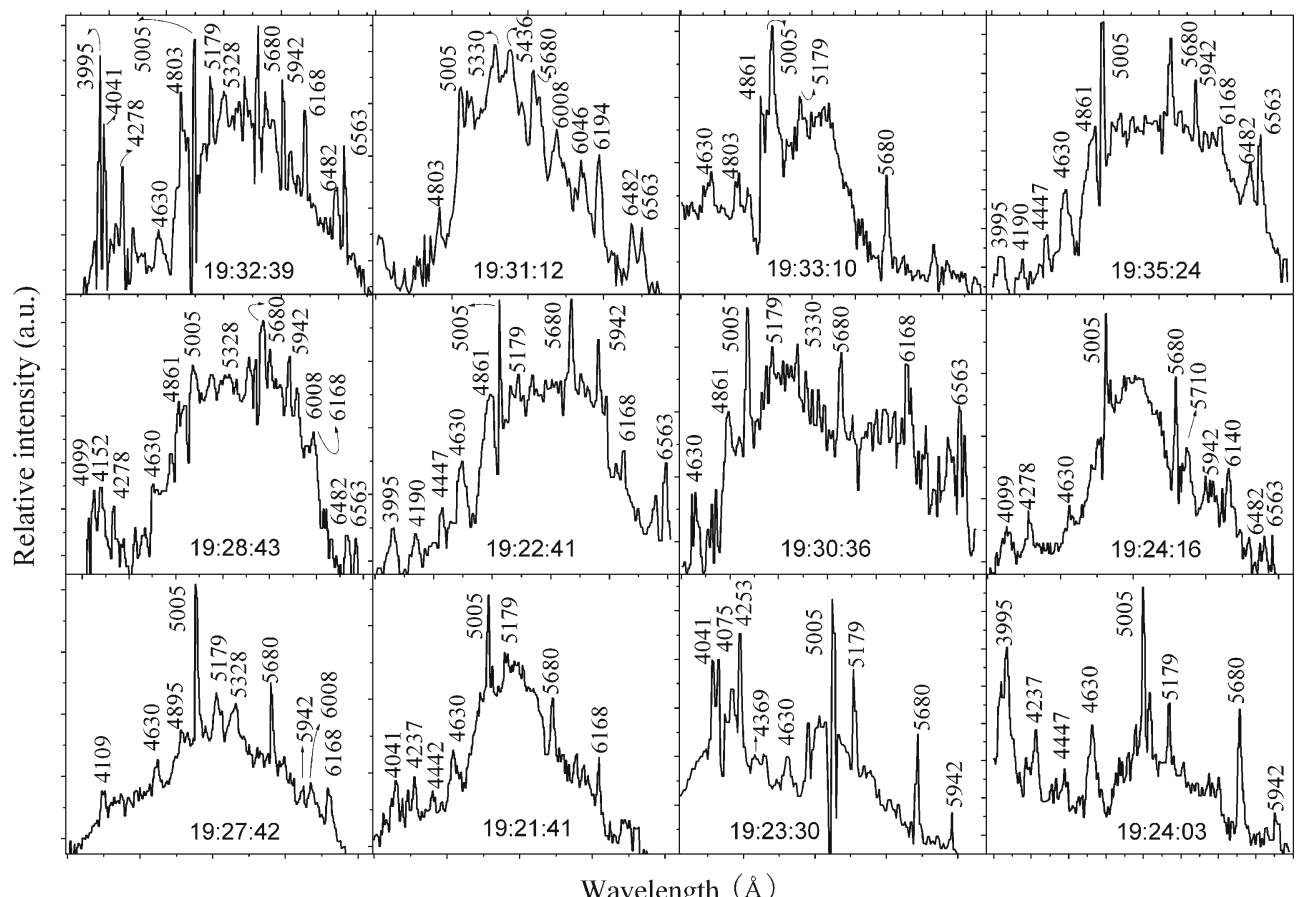

Figure 3. The relative intensity of lines in the optical spectra of lightning discharges. It is calculated from colour stripe optical spectra obtained by the camcorder with grating. Line identification is based on the characteristic lines (4630, 5005, $5680,6563 \AA$, etc.).

the attenuation at $400 \mathrm{~Hz}$ is a factor 3 but at 50 $100 \mathrm{~Hz}$, it is negligible. It follows that the observed thunder frequency spectra are affected by attenuation at the high-frequency end, and hence the peak frequency is likely to be distance-dependent. Last but not the least, the peak frequencies of the cases range from 210 to $860 \mathrm{~Hz}$.

\subsection{The relation between peak frequency and some lightning parameters}

It is well-known that a given section of the return stroke channel reaches a temperature of about $30,000 \mathrm{~K}$ in a duration of less than $10 \mu \mathrm{s}$ (Dubovoy et al 1995). It follows that the channel pressure must rise in response to the temperature rise since the time is insufficient for the channel particle density to change appreciably (D'Angola et al 2008). Calculations from spectroscopic data indicate an average channel pressure of about 10 bar during the first $5 \mu \mathrm{s}$. Such a channel overpressure results in an expansion of the channel behind a shock wave. As the channel expands, its pressure decreases towards atmospheric level on a time scale of tens of microseconds. Return strokes are the strongest generators of audible thunder. Furthermore, intense ionization occurs during the evolution of ionization-thermal instability and subsequent heating to the final temperature (Uman et al 2001). So, there is a relationship between the thunder characteristic and lightning parameters. Certain features of the lightning discharge have been identified as having a definite influence on the nature of thunder (Holmes and Brook 1971). Most of the energy input is thought to be spent in radiation, ionization and expansion of the channel (Rakov and Uman 2003).

As representative, the 12 lightning optical spectra are given in figure 3 . In a general way, lines lap over the continuum. Line intensity, for most of the lines, is contributed by a set of multi-ply transitions, where dominant wavelength carries the largest transition intensity. For example, a NI emission line at $5005 \AA$, which exists almost in every lightning spectrum, includes the three transitions $2 \mathrm{p}\left({ }^{2} \mathrm{P}^{\mathrm{o}}\right) 3 \mathrm{p}{ }^{3} \mathrm{D}_{3}-2 \mathrm{p}\left({ }^{2} \mathrm{P}^{\mathrm{o}}\right) 3 \mathrm{~d}{ }^{3} \mathrm{~F}_{4}, 2 \mathrm{p}\left({ }^{2} \mathrm{P}^{\mathrm{o}}\right) 3 \mathrm{p}$ ${ }^{3} \mathrm{~S}_{1}-2 \mathrm{p}\left({ }^{2} \mathrm{P}^{\mathrm{o}}\right) 3 \mathrm{~d}{ }^{3} \mathrm{P}_{2}$ and $2 \mathrm{p}\left({ }^{2} \mathrm{P}^{\mathrm{o}}\right) 3 \mathrm{~s}{ }^{3} \mathrm{P}_{1}^{\mathrm{o}}-2 \mathrm{p}\left({ }^{2} \mathrm{P}^{\mathrm{o}}\right) 3 \mathrm{p}$ ${ }^{3} \mathrm{~S}_{1}$; and the excitation potential is $23.142 \mathrm{ev}$, $23.415 \mathrm{ev}$ and $20.940 \mathrm{ev}$; and the wavelength is $5006.69,5008.76$ and $5012.03 \AA$, respectively. The weighed wavelength is $5007.85 \AA$, which is the result from the percentage of each line in the group of multi-ply lines. According to plasma theories, it can be seen that different lightning spectrum distribution indicates different lightning discharge intensity. Some transition parameters are listed in table 1. Lightning spectra, naturally, include lines of molecular and atomic oxygen and nitrogen. No doubly charged ions have been detected in these 
Table 1. Transition parameters of lines excited in the 12 lightning spectra.

\begin{tabular}{|c|c|c|c|c|c|}
\hline \multicolumn{2}{|c|}{ Wavelength $(\AA)$} & \multirow{2}{*}{$\begin{array}{l}\text { Emission } \\
\text { particle }\end{array}$} & \multirow[b]{2}{*}{ Transition } & \multirow{2}{*}{$\begin{array}{c}\text { Upper excitation } \\
\text { energy }(\mathrm{eV})\end{array}$} & \multirow[b]{2}{*}{$g_{i} A_{\mathrm{mi}}$} \\
\hline$\lambda_{\text {obs }}$ & $\lambda_{\text {cal }}$ & & & & \\
\hline 3995 & 3994.99 & NII & $2 \mathrm{~s}^{2} 2 \mathrm{p}\left({ }^{2} \mathrm{P}^{\mathrm{o}}\right) 3 \mathrm{~s}{ }^{1} \mathrm{P}_{1}^{\mathrm{o}}-2 \mathrm{~s}^{2} 2 \mathrm{p}\left({ }^{2} \mathrm{P}^{\mathrm{o}}\right) 3 \mathrm{p}{ }^{1} \mathrm{D}_{2}$ & 21.599 & $4.050 \mathrm{e}+00$ \\
\hline \multirow[t]{2}{*}{4041} & 4041.31 & NII & & & \\
\hline & 4041.95 & OII & $2 \mathrm{~s}^{2} 2 \mathrm{p}^{2}\left({ }^{3} \mathrm{P}\right) 3 \mathrm{~d}{ }^{4} \mathrm{~F}_{5 / 2}-2 \mathrm{~s}^{2} 2 \mathrm{p}^{2}\left({ }^{3} \mathrm{P}\right) 4 \mathrm{fF}^{2}[2]_{3 / 2}^{\mathrm{o}}$ & 31.654 & \\
\hline 4075 & 4075.86 & OII & $2 \mathrm{~s}^{2} 2 \mathrm{p}^{2}\left({ }^{3} \mathrm{P}\right) 3 \mathrm{p}{ }^{4} \mathrm{D}_{7 / 2}^{\mathrm{o}}-2 \mathrm{~s}^{2} 2 \mathrm{p}^{2}\left({ }^{3} \mathrm{P}\right) 3 \mathrm{~d}{ }^{4} \mathrm{~F}_{9 / 2}$ & 28.702 & $1.584 \mathrm{e}+01$ \\
\hline \multirow[t]{2}{*}{4099} & 4099.94 & $\mathrm{NI}$ & $2 \mathrm{~s}^{2} 2 \mathrm{p}^{2}\left({ }^{3} \mathrm{P}\right) 3 \mathrm{~s}^{2} \mathrm{P}_{1 / 2}-2 \mathrm{~s}^{2} 2 \mathrm{p}^{2}\left({ }^{1} \mathrm{D}\right) 3 \mathrm{p}^{2} \mathrm{D}_{3 / 2}^{\mathrm{o}}$ & 13.701 & $6.960 \mathrm{e}-02$ \\
\hline & 4102.90 & NII & $2 \mathrm{~s} 2 \mathrm{p}^{2}\left({ }^{4} \mathrm{P}\right) 3 \mathrm{~s}{ }^{5} \mathrm{P}-2 \mathrm{~s}^{2} 2 \mathrm{p}\left({ }^{2} \mathrm{P}^{\mathrm{o}}\right) 3 \mathrm{~d}{ }^{5} \mathrm{D}^{\mathrm{o}}$ & 26.263 & $1.340 \mathrm{e}-02$ \\
\hline 4109 & 4109.94 & NI & $2 \mathrm{~s}^{2} 2 \mathrm{p}^{2}\left({ }^{3} \mathrm{P}\right) 3 \mathrm{~s}^{2} \mathrm{P}_{3 / 2}-2 \mathrm{~s}^{2} 2 \mathrm{p}^{2}\left({ }^{1} \mathrm{D}\right) 3 \mathrm{p}^{2} \mathrm{D}_{5 / 2}^{\mathrm{o}}$ & 13.706 & $1.560 \mathrm{e}-01$ \\
\hline 4152 & 4151.48 & NI & $2 \mathrm{~s}^{2} 2 \mathrm{p}^{2}\left({ }^{3} \mathrm{P}\right) 3 \mathrm{~s}{ }^{4} \mathrm{P}_{5 / 2}-2 \mathrm{~s}^{2} 2 \mathrm{p}^{2}\left({ }^{3} \mathrm{P}\right) 4 \mathrm{p}{ }^{4} \mathrm{~S}_{3 / 2}^{\mathrm{o}}$ & 13.322 & $6.060 \mathrm{e}-02$ \\
\hline 4176 & 4169.22 & OII & $2 \mathrm{~s}^{2} 2 \mathrm{p}^{2}\left({ }^{3} \mathrm{P}\right) 3 \mathrm{p}{ }^{4} \mathrm{P}_{5 / 2}^{\mathrm{o}}-2 \mathrm{~s}^{2} 2 \mathrm{p}^{2}\left({ }^{3} \mathrm{P}\right) 3 \mathrm{~d}{ }^{4} \mathrm{P}_{5 / 2}$ & 28.817 & $1.494 \mathrm{e}+00$ \\
\hline \multirow[t]{2}{*}{4237} & 4237.74 & NII & $2 \mathrm{~s}^{2} 2 \mathrm{p}\left({ }^{2} \mathrm{P}^{\mathrm{o}}\right) 3 \mathrm{p}{ }^{1} \mathrm{D}_{2}-2 \mathrm{~s}^{2} 2 \mathrm{p}\left({ }^{2} \mathrm{P}^{\mathrm{o}}\right) 4 \mathrm{~s}^{1} \mathrm{P}_{1}^{\mathrm{o}}$ & 24.531 & $3.240 \mathrm{e}+00$ \\
\hline & 4233.27 & OI & $2 \mathrm{~s}^{2} 2 \mathrm{p}^{3}\left({ }^{4} \mathrm{~S}^{\mathrm{o}}\right) 4 \mathrm{p}^{3} \mathrm{P}_{2}-2 \mathrm{~s}^{2} 2 \mathrm{p}^{3}\left({ }^{2} \mathrm{D}_{3 / 2}^{\mathrm{o}}\right) 3 \mathrm{~d}^{3} \mathrm{P}_{2}^{\mathrm{o}}$ & 15.284 & $2.020 \mathrm{e}-02$ \\
\hline 4278 & 4278.13 & NI & $2 \mathrm{~s}^{2} 2 \mathrm{p}^{2}\left({ }^{3} \mathrm{P}\right) 3 \mathrm{p}{ }^{2} \mathrm{D}_{3 / 2}^{\mathrm{o}}-2 \mathrm{~s}^{2} 2 \mathrm{p}^{2}\left({ }^{1} \mathrm{D}\right) 3 \mathrm{~d}^{2} \mathrm{D}_{3 / 2}$ & 14.897 & $2.004 \mathrm{e}-01$ \\
\hline \multirow[t]{2}{*}{4369} & 4368.26 & OI & $2 \mathrm{~s}^{2} 2 \mathrm{p}^{3}\left({ }^{4} \mathrm{~S}^{\mathrm{o}}\right) 3 \mathrm{~s}^{3} \mathrm{~S}_{1}^{\mathrm{o}}-2 \mathrm{~s}^{2} 2 \mathrm{p}^{3}\left({ }^{4} \mathrm{~S}^{\mathrm{o}}\right) 4 \mathrm{p}^{2} \mathrm{P}_{1}$ & 12.357 & $2.274 \mathrm{e}-02$ \\
\hline & 4369.27 & OII & $2 \mathrm{~s}^{2} 2 \mathrm{p}^{2}\left({ }^{3} \mathrm{P}\right) 3 \mathrm{p}^{2} \mathrm{D}_{3 / 2}^{\mathrm{o}}-2 \mathrm{~s}^{2} 2 \mathrm{p}^{2}\left({ }^{3} \mathrm{P}\right) 3 \mathrm{~d}^{2} \mathrm{D}_{3 / 2}$ & 29.058 & $1.428 \mathrm{e}+00$ \\
\hline 4442 & 4442.45 & NI & $2 \mathrm{~s}^{2} 2 \mathrm{p}^{2}\left({ }^{3} \mathrm{P}\right) 3 \mathrm{p}{ }^{2} \mathrm{P}_{3 / 2}^{\mathrm{o}}-2 \mathrm{~s}^{2} 2 \mathrm{p}^{2}\left({ }^{1} \mathrm{D}\right) 3 \mathrm{~d}^{2} \mathrm{P}_{3 / 2}^{\mathrm{o}}$ & 14.916 & $1.524 \mathrm{e}-01$ \\
\hline \multirow[t]{2}{*}{4447} & 4447.03 & NII & $2 \mathrm{~s}^{2} 2 \mathrm{p}\left({ }^{2} \mathrm{P}^{\mathrm{o}}\right) 3 \mathrm{p}{ }^{1} \mathrm{P}_{1}-2 \mathrm{~s}^{2} 2 \mathrm{p}\left({ }^{2} \mathrm{P}^{\mathrm{o}}\right) 3 \mathrm{~d}{ }^{1} \mathrm{D}_{2}^{\mathrm{o}}$ & 23.196 & $3.420 \mathrm{e}+00$ \\
\hline & 4444.68 & OII & $2 \mathrm{~s}^{2} 2 \mathrm{p}^{2}\left({ }^{1} \mathrm{D}\right) 3 \mathrm{p}{ }^{2} \mathrm{~F}_{7 / 2}^{\mathrm{o}}-2 \mathrm{~s}^{2} 2 \mathrm{p}^{2}\left({ }^{1} \mathrm{D}\right) 3 \mathrm{~d}^{2} \mathrm{~F}_{5 / 2}$ & 31.143 & $2.016 \mathrm{e}-01$ \\
\hline 4630 & 4630.77 & NII & $2 \mathrm{p}\left({ }^{2} \mathrm{P}^{\mathrm{o}}\right) 3 \mathrm{~s}{ }^{3} \mathrm{P}_{2}-2 \mathrm{p}\left({ }^{2} \mathrm{P}^{\mathrm{o}}\right) 3 \mathrm{p}{ }^{3} \mathrm{P}_{2}$ & 21.160 & $3.860 \mathrm{e}+00$ \\
\hline 4803 & 4804.69 & NII & $2 \mathrm{~s}^{2} 2 \mathrm{p}\left({ }^{2} \mathrm{P}^{\mathrm{o}}\right) 3 \mathrm{p}{ }^{3} \mathrm{D}_{3}-2 \mathrm{~s}^{2} 2 \mathrm{p}\left({ }^{2} \mathrm{P}^{\mathrm{o}}\right) 3 \mathrm{~d}^{3} \mathrm{D}_{3}^{\mathrm{O}}$ & 23.246 & $9.540 \mathrm{e}-01$ \\
\hline 4861 & 4861.30 & $\mathrm{H} \beta$ & $2^{2} \mathrm{P}^{\mathrm{o}}-4^{2} \mathrm{D}$ & & \\
\hline 4895 & 4895.12 & NII & $2 \mathrm{~s}\left({ }^{2} \mathrm{~S}\right) 2 \mathrm{p}^{3}{ }^{1} \mathrm{D}_{2}^{\mathrm{o}}-2 \mathrm{~s}^{2} 2 \mathrm{p}\left({ }^{2} \mathrm{P}^{\mathrm{o}}\right) 3 \mathrm{p}{ }^{1} \mathrm{P}_{1}$ & 20.409 & $2.130 \mathrm{e}-01$ \\
\hline \multirow[t]{3}{*}{5005} & 5006.69 & NII & $2 \mathrm{p}\left({ }^{2} \mathrm{P}^{\mathrm{o}}\right) 3 \mathrm{p}{ }^{3} \mathrm{D}_{3}-2 \mathrm{p}\left({ }^{2} \mathrm{P}^{\mathrm{o}}\right) 3 \mathrm{~d}^{3} \mathrm{~F}_{4}$ & 23.142 & $8.120 \mathrm{e}+00$ \\
\hline & 5008.76 & NII & $2 \mathrm{p}\left({ }^{2} \mathrm{P}^{\mathrm{o}}\right) 3 \mathrm{p}{ }^{3} \mathrm{~S}_{1}-2 \mathrm{p}\left({ }^{2} \mathrm{P}^{\mathrm{o}}\right) 3 \mathrm{~d}^{3} \mathrm{P}_{2}$ & 23.415 & $2.367 \mathrm{e}+00$ \\
\hline & 5012.03 & NII & $2 \mathrm{p}\left({ }^{2} \mathrm{P}^{\mathrm{o}}\right) 3 \mathrm{~s}{ }^{3} \mathrm{P}_{1}^{\mathrm{o}}-2 \mathrm{p}\left({ }^{2} \mathrm{P}^{\mathrm{o}}\right) 3 \mathrm{p}{ }^{3} \mathrm{~S}_{1}$ & 20.940 & $6.570 \mathrm{e}-01$ \\
\hline \multirow[t]{2}{*}{5179} & 5179.52 & NII & $2 \mathrm{~s} 2 \mathrm{p}^{2}\left({ }^{4} \mathrm{P}\right) 3 \mathrm{p}{ }^{5} \mathrm{D}_{4}^{\mathrm{o}}-2 \mathrm{~s} 2 \mathrm{p}^{2}\left({ }^{4} \mathrm{P}\right) 3 \mathrm{~d}{ }^{5} \mathrm{~F}_{5}$ & 30.139 & $9.630 \mathrm{e}+00$ \\
\hline & 5179.31 & NII & $2 \mathrm{~s} 2 \mathrm{p}^{2}\left({ }^{4} \mathrm{P}\right) 3 \mathrm{p}{ }^{5} \mathrm{P}_{3}^{\mathrm{o}}-2 \mathrm{~s} 2 \mathrm{p}^{2}\left({ }^{4} \mathrm{P}\right) 3 \mathrm{~d}{ }^{5} \mathrm{D}_{4}$ & 30.373 & $6.069 \mathrm{e}+00$ \\
\hline 5328 & 5328.62 & $\mathrm{NI}$ & $2 \mathrm{~s} 2 \mathrm{p}^{4}{ }^{4} \mathrm{P}_{5 / 2}-2 \mathrm{~s}^{2} 2 \mathrm{p}^{2}\left({ }^{3} \mathrm{P}\right) 4 \mathrm{p}{ }^{4} \mathrm{D}_{7 / 2}^{\mathrm{o}}$ & 13.250 & $1.230 \mathrm{e}-02$ \\
\hline \multirow[t]{2}{*}{5330} & 5330.71 & OI & $2 \mathrm{~s}^{2} 2 \mathrm{p}^{3}\left({ }^{4} \mathrm{~S}^{\mathrm{O}}\right) 3 \mathrm{p}{ }^{5} \mathrm{P}_{3}-2 \mathrm{~s}^{2} 2 \mathrm{p}^{3}\left({ }^{4} \mathrm{~S}^{\mathrm{O}}\right) 5 \mathrm{~d}{ }^{5} \mathrm{D}_{4}^{\mathrm{o}}$ & 13.066 & $1.897 \mathrm{e}-01$ \\
\hline & 5328.56 & NI & $2 \mathrm{~s} 2 \mathrm{p}^{4}{ }^{4} \mathrm{P}_{5 / 2}-2 \mathrm{~s}^{2} 2 \mathrm{p}^{3}\left({ }^{3} \mathrm{P}\right) 4 \mathrm{p}{ }^{4} \mathrm{D}_{7 / 2}^{\mathrm{o}}$ & 13.250 & $1.230 \mathrm{e}-02$ \\
\hline 5436 & 5436.27 & OI & $2 \mathrm{~s}^{2} 2 \mathrm{p}^{3}\left({ }^{4} \mathrm{~S}^{\mathrm{o}}\right) 3 \mathrm{p}{ }^{5} \mathrm{P}_{3}-2 \mathrm{~s}^{2} 2 \mathrm{p}^{3}\left({ }^{4} \mathrm{~S}^{\mathrm{o}}\right) 6 \mathrm{~s}^{5} \mathrm{~S}_{2}^{\mathrm{O}}$ & 13.021 & $1.260 \mathrm{e}-01$ \\
\hline 5680 & 5681.17 & NII & $2 \mathrm{p}\left({ }^{2} \mathrm{P}^{\mathrm{o}}\right) 3 \mathrm{~s}{ }^{3} \mathrm{P}_{2}-2 \mathrm{p}\left({ }^{2} \mathrm{P}^{\mathrm{o}}\right) 3 \mathrm{p}{ }^{3} \mathrm{D}_{3}$ & 20.665 & $2.625 \mathrm{e}+00$ \\
\hline 5710 & 5710.69 & NII & $2 \mathrm{~s}^{2} 2 \mathrm{p}\left({ }^{2} \mathrm{P}^{\mathrm{o}}\right) 3 \mathrm{~s}^{3} \mathrm{P}_{2}-2 \mathrm{~s}^{2} 2 \mathrm{p}\left({ }^{2} \mathrm{P}^{\mathrm{o}}\right) 3 \mathrm{p}{ }^{3} \mathrm{D}_{2}$ & 20.653 & $6.200 \mathrm{e}-01$ \\
\hline 5942 & 5943.18 & NII & $2 \mathrm{p}\left({ }^{2} \mathrm{P}^{\mathrm{o}}\right) 3 \mathrm{p}{ }^{3} \mathrm{P}_{2}-2 \mathrm{p}\left({ }^{2} \mathrm{P}^{\mathrm{o}}\right) 3 \mathrm{~d}^{3} \mathrm{D}_{3}$ & 23.246 & $2.770 \mathrm{e}+00$ \\
\hline 6008 & 6008.38 & NI & $2 \mathrm{p}^{2}\left({ }^{3} \mathrm{P}\right) 3 \mathrm{p}{ }^{2} \mathrm{~S}_{1 / 2}^{\mathrm{o}}-2 \mathrm{p}^{2}\left({ }^{3} \mathrm{P}\right) 4 \mathrm{~d}^{2} \mathrm{P}_{3 / 2}$ & 13.665 & $7.160 \mathrm{e}-02$ \\
\hline 6046 & 6046.40 & $\mathrm{OI}$ & $2 \mathrm{~s}^{2} 2 \mathrm{p}^{3}\left({ }^{4} \mathrm{~S}^{\mathrm{O}}\right) 3 \mathrm{p}{ }^{3} \mathrm{P}_{2}-2 \mathrm{~s}^{2} 2 \mathrm{p}^{3}\left({ }^{4} \mathrm{~S}^{\mathrm{O}}\right) 6 \mathrm{~s}{ }^{3} \mathrm{~S}_{1}^{\mathrm{O}}$ & 13.039 & $8.750 \mathrm{e}-02$ \\
\hline \multirow[t]{2}{*}{6168} & 6167.98 & NII & $2 \mathrm{p}\left({ }^{2} \mathrm{P}^{\mathrm{o}}\right) 3 \mathrm{~d}^{3} \mathrm{~F}_{4}^{\mathrm{o}}-2 \mathrm{p}\left({ }^{2} \mathrm{P}^{\mathrm{o}}\right) 4 \mathrm{p}^{3} \mathrm{D}_{3}$ & 25.151 & $2.385 \mathrm{e}+00$ \\
\hline & 6158.15 & OI & $2 \mathrm{p}^{3}\left({ }^{4} \mathrm{~S}^{\mathrm{o}}\right) 3 \mathrm{p}{ }^{5} \mathrm{P}_{3}-2 \mathrm{p}^{3}\left({ }^{4} \mathrm{~S}^{\mathrm{o}}\right) 4 \mathrm{~d}^{5} \mathrm{D}_{4}^{\mathrm{o}}$ & 12.754 & $5.334 \mathrm{e}-01$ \\
\hline 6194 & 6194.28 & $\mathrm{NI}$ & $2 \mathrm{~s}^{2} 2 \mathrm{p}^{2}\left({ }^{3} \mathrm{P}\right) 3 \mathrm{p}^{2} \mathrm{D}_{3 / 2}^{\mathrm{o}}-2 \mathrm{~s}^{2} 2 \mathrm{p}^{2}\left({ }^{3} \mathrm{P}\right) 5 \mathrm{~d}^{2} \mathrm{D}_{3 / 2}$ & 14.001 & $4.840 \mathrm{e}-03$ \\
\hline \multirow[t]{2}{*}{6482} & 6482.09 & NII & $2 \mathrm{p}\left({ }^{2} \mathrm{P}^{\mathrm{o}}\right) 3 \mathrm{~s}{ }^{1} \mathrm{P}_{1}^{\mathrm{o}}-2 \mathrm{p}\left({ }^{2} \mathrm{P}^{\mathrm{o}}\right) 3 \mathrm{p}{ }^{1} \mathrm{P}_{1}$ & 20.409 & $9.030 \mathrm{e}-01$ \\
\hline & 6484.29 & NI & $2 \mathrm{p}^{2}\left({ }^{3} \mathrm{P}\right) 3 \mathrm{p}{ }^{4} \mathrm{D}_{5 / 2}^{\mathrm{o}}-2 \mathrm{p}^{2}\left({ }^{3} \mathrm{P}\right) 4 \mathrm{~d}{ }^{4} \mathrm{~F}_{7 / 2}$ & 12.088 & $2.520 \mathrm{e}-01$ \\
\hline 6563 & 6562.86 & $\mathrm{H} \alpha$ & $2 \mathrm{p}^{2} \mathrm{P}_{3 / 2}^{\mathrm{o}}-3 \mathrm{~d}^{2} \mathrm{D}_{1 / 2}$ & 12.088 & \\
\hline
\end{tabular}

spectra, indicating that the temperature does not exceed $30,000 \mathrm{~K}$.

The calculation results given in this work (table 2) show a fairly good agreement with the measurements. As illustrated in figure 3, the NII emission lines 5005 and $5179 \AA$, whose excitation potentials are relative high, are very intense in the lightning spectra 19:23:30, 19:24:16, 19:24:03, 19:27:42, 19:35:24 and 19:21:41. Moreover, it can be known through the qualitative analysis of optic data and electric data that these six events are the more intense lightning discharges. There are many NI emission lines in the 19:28:43 spectrum, such as 4099, 4152, 4278, 5328 and $6008 \AA$. This implies that this lightning is the weakest lightning discharge among the 12 considered events. At the same time, there are some OII emission lines in 19:24:16 and 19:23:30 spectra, these two lightning 
Table 2. Thunder peak frequencies and the parameters of lightning discharge channels.

\begin{tabular}{|c|c|c|c|c|c|c|c|}
\hline Name & $\begin{array}{c}\text { Peak } \\
\text { frequency } \\
\quad(\mathrm{Hz})\end{array}$ & $\begin{array}{c}\text { Channel } \\
\text { temperature } \\
(\mathrm{K})\end{array}$ & $\begin{array}{c}\text { Electron } \\
\text { density } \\
\left(10^{18} \mathrm{~cm}^{-3}\right)\end{array}$ & $\begin{array}{c}\text { Ionization } \\
\text { degree } \\
(\%)\end{array}$ & $\begin{array}{c}\text { Channel } \\
\text { pressure } \\
(\mathrm{MPa})\end{array}$ & $\begin{array}{l}\text { Thunder } \\
\text { lasting } \\
\text { time(s) }\end{array}$ & $\begin{array}{c}\text { Lightning } \\
\text { distance } \\
(\mathrm{m})\end{array}$ \\
\hline $\mathrm{A}(19: 28: 43)$ & 750 & 23300 & 0.217 & 96.53 & 0.201 & 7.4 & 4420 \\
\hline $\mathrm{B}(19: 33: 10)$ & 520,860 & 23600 & 0.453 & 97.17 & 0.225 & 6.9 & 3400 \\
\hline $\mathrm{C}(19: 30: 36)$ & 300,700 & 24200 & 0.585 & 96.30 & 0.232 & 10.0 & 4420 \\
\hline $\mathrm{D}(19: 31: 12)$ & 540 & 24700 & 0.623 & 96.80 & 0.614 & 9.3 & 3400 \\
\hline $\mathrm{E}(19: 32: 39)$ & 500 & 25500 & 0.861 & 97.32 & 0.664 & 7.9 & 2040 \\
\hline $\mathrm{F}(19: 22: 41)$ & 250,710 & 26000 & 0.994 & 97.99 & 1.309 & 8.8 & 5780 \\
\hline $\mathrm{G}(19: 21: 41)$ & 230 & 26200 & 1.102 & 98.13 & 1.311 & 5.3 & 6460 \\
\hline $\mathrm{H}(19: 35: 24)$ & 260,600 & 26500 & 1.299 & 96.24 & 1.375 & 9.4 & 4080 \\
\hline $\mathrm{I}(19: 27: 42)$ & 280,680 & 27300 & 1.415 & 97.13 & 1.806 & 5.8 & 5780 \\
\hline $\mathrm{J}(19: 24: 03)$ & 250,500 & 27700 & 1.486 & 97.10 & 1.737 & 10.0 & 7140 \\
\hline $\mathrm{K}(19: 24: 16)$ & 220 & 28000 & 2.750 & 97.70 & 1.832 & 5.2 & 5780 \\
\hline $\mathrm{L}(19: 23: 30)$ & 210 & 29600 & 3.299 & 95.51 & 2.655 & 4.8 & 7140 \\
\hline
\end{tabular}

discharges are relatively strong. It fits just with the result from optic or electric data.

According to the theories on plasma and using the wavelengths, relative intensities and some transition parameters of lines in lightning spectra, the parameters of lightning discharge channels are calculated. Table 2 provides thunder peak frequencies and channel temperature, electron density, ionizability, channel pressure, thunder lasting time and lightning distance. Lightning distance is determined from the time interval between the electromagnetic signal recorded at the optical observation site and the first sound of thunder. Channel pressures change in the range of several to tens of bars. The electron density, calculated by using Saha equations, is from $1 \mathrm{E} 17$ to $1 \mathrm{E} 18 \mathrm{~cm}^{-3}$. The results are similar to those obtained by Orville (1968). According to Orville $(1968,1980)$, the electron density was about $8 \times 1 \mathrm{E} 17 \mathrm{~cm}^{-3}$, which is obtained from comparison of the measured Stark width of the $\mathrm{H} \alpha$ line radiated by hydrogen atoms with the theoretical Stark width of the $\mathrm{H} \alpha$ line. The average channel pressure was about 8 bar. So the calculation results in this work fit well with the references.

Calculations show that peak frequency drops from 750 to $210 \mathrm{~Hz}$ with temperature increasing from $23,300-29,600 \mathrm{~K}$ (figure 4), similar to the

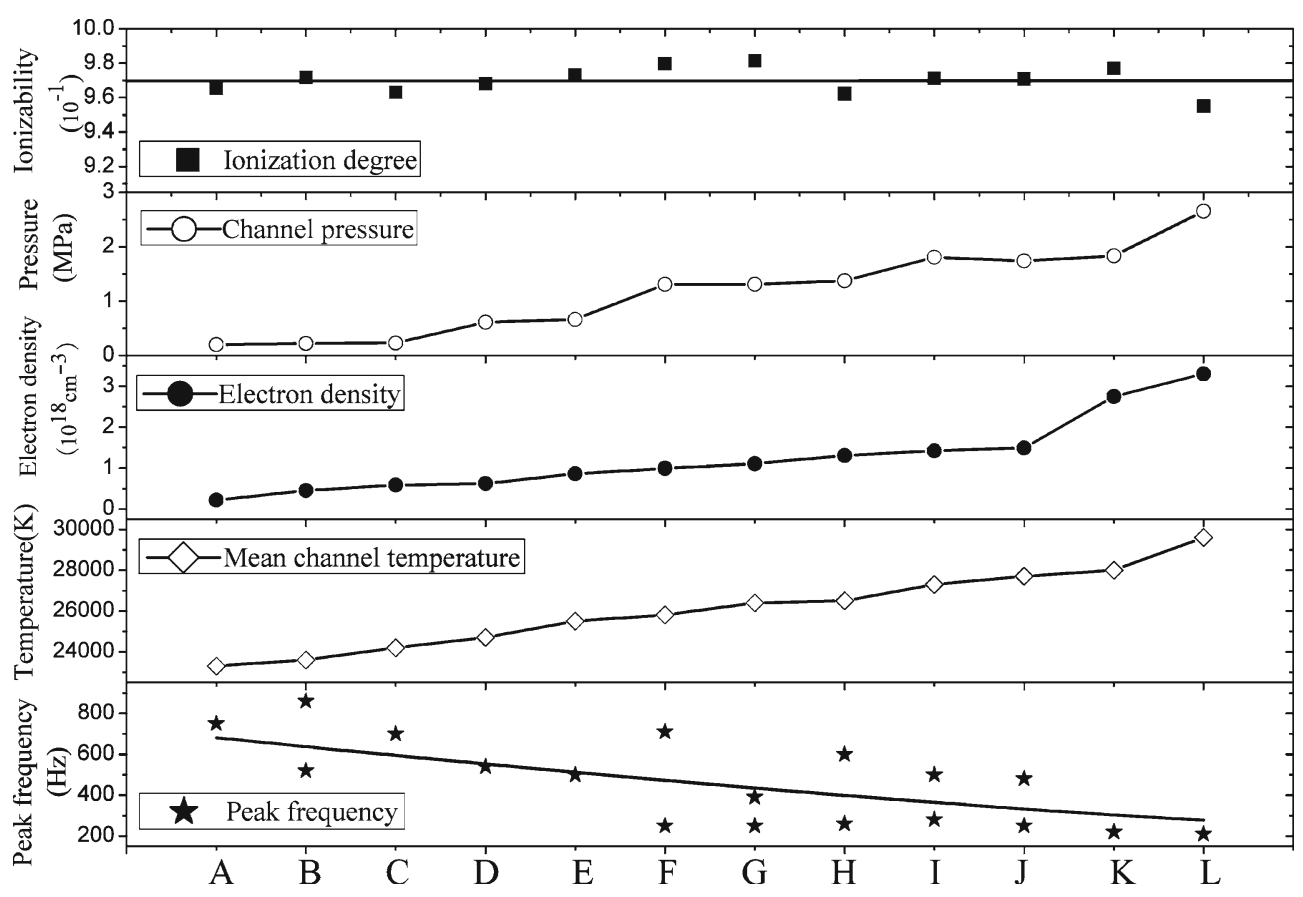

Figure 4. The relation between thunder peak frequency and some lightning parameters. The order of abscissa establishes by mean channel temperature from low to high, in this case, the thunder dominant frequency shows trends of falling away. 
trend shown by Few (1995). According to Few's thunder theory, the thunder peak frequency is in inverse proportion to the square root of the channel energy per length unit. The energy input is dissipated in raising the channel temperature (Capitelli et al 2000), therefore the temperature is high if the energy is large. As follows, there are some experimental data which can further validate the conclusion. Depasse (1994) measured the acoustic signals of $70 \mathrm{~m}$ from rocket-triggered lightning in France and found that the dominant frequency ranged from 300 to $900 \mathrm{~Hz}$ for individual strokes. Uman et al (1970) Fourier-transformed a typical shock waveform from a spark and found a peak frequency of $1400 \mathrm{~Hz}$. According to Colgate and Mckee (1969), the dominant frequency of natural thunder is approximately $135 \mathrm{~Hz}$ (the distance was more than $8 \mathrm{~km}$ ). Of course, the peak frequency of natural thunder should be higher if propagation effects had been taken into account. It is well-known that natural lightning is more powerful than rocket-triggered lightning, and rockettriggered lightning is more powerful than spark discharge. From these data, it can be clearly seen that the more powerful the lightning is, the lesser the relative thunder dominant frequency is.

In addition (figure 4), channel pressure and electron density increase with temperature, and have contrary trend with thunder peak frequency. While ionization degrees are close to saturation under such conditions, and remain constant. Therefore, ionizability is almost independent of the natural thunder peak frequency.

\section{Conclusions}

In this work, the 12 lightning flashes are studied using two different methods: (a) It is deduced in the generation location of lightning considering the effects of finite amplitude propagation and attenuation by air and concluded that thunder peak frequency is distance-dependent; (b) Based on transition parameters of lightning spectra lines, and using Saha equations, charge conservation equations and particle conservation equations, lightning channel parameters such as temperature and electron density are calculated. The principal results and contributions, which follow from studies presented in this paper, can be summarized as follows.

Firstly, the characteristic peak frequency varies from $210-280 \mathrm{~Hz}$ for the 12 events. And the peak frequencies range from $210-860 \mathrm{~Hz}$ once the thunders are calculated backwards to the generation location. Observed thunder frequency spectra are affected by attenuation and also by the lengthening of acoustic waves at the high-frequency end.
Usually, in the observation location, the peak frequency of different thunders show trends of falling away with increasing distances. Amplitude of the high-frequency zone reduces faster than that of low-frequency zone.

Secondly, certain features of the lightning discharge have been identified as having a definitive influence on natural thunder. Thunder frequency distribution is strongly lightning channel-parameters-dependent. Briefly, the lower the thunder peak frequency is, the higher the averaged channel temperature, the channel pressure, and the electron density are. However, mean ionization degrees show few tendencies with other parameters because these lightning channels are almost completely ionized.

\section{Acknowledgements}

This work would not have been possible without generous contributions from a large group of people. The authors gratefully acknowledge discussions with X S Qie and G S Zhang on the subject of audible thunder. They are also indebted to T L Zhang and his cooperators (Cold and Arid Regions Environment and Engineering Research Institute, Chinese Academy of Sciences) for giving access to data from the Electric Field Experiment, which provided electric field data to compare the intensity of lightning. The authors are thankful to the editor and reviewers for their valuable suggestions and critical comments which improved the quality of the paper.

\section{References}

Assink J D, Evers L G, Holleman I and Paulssen H 2008 Characterization of infrasound from lightning; Geophys. Res. Lett. 35 L15802.

Bass H E and Losely R E 1975 Effect of atmospheric absorption on the acoustic power spectrum of thunder; J. Acoust. Soc. Am. 57 822-823.

Capitelli M, Gorse C et al 2000 Collision integrals of hightemperature air species; Thermophys. Heat Transf. 14(2) 259-268.

Colgate S A and Mckee C 1969 Electrostatic sound in clouds and lightning; J. Geophys. Res. 74 5379-5389.

D'Angola A et al 2008 Thermodynamic and transport properties in equilibrium air plasmas in wide pressure and temperature range; Eur. Phys. J. D 46 129-150.

Depasse P 1994 Lightning acoustic signature; J. Geophys. Res. 99 25,933-25,940.

Dubovoy E I et al 1995 Measurement and numerical modeling of radio sounding reflection from a lightning channel; J. Geophys. Res. 100 1497-1502.

Farges T and Blanc E 2010 Characteristics of infrasound from lightning and sprites near thunderstorm areas; J. Geophys. Res. 115 A00E31.

Few A A 1969 Power spectrum of thunder; J. Geophys. Res. 74 6926-6934. 
Few A A 1995 Acoustic radiations from lightning; In: Handbook of atmospheric electrodynamics (ed.) Volland $\mathrm{H}$ (Boca Raton, Florida: CRC Press), pp. 111-131.

Holmes C R and Brook M 1971 On the power spectrum and mechanism of thunder, J. Geophys. Res. 76 21062109.

Otterman J 1959 Finite-amplitude propagate effect on shock wave travel times from explosions at high altitudes; J. Acoust. Soc. Am. 31 470-474.

OuYang Y H and Yuan P et al 2006 Temperature study on lightning return stroke in the coastal area of Guangdong; Spectroscopy and Spectral Analysis 26 1988-1992 (in Chinese).

Orville R E 1968 A high-speed time-resolved spectroscopic study of the lightning return stroke: Part II. A quantitative analysis; J. Atmos. Sci. 25 839-851.
Orville R E 1980 Daylight spectra of individual flashes in the 370-690 nm region; J. Appl. Meteorol. 19 470-473.

Pasko V P 2009 Mechanism of lightning-associated infrasonic pulses from thunderclouds; J. Geophys. Res. 114 D08205.

Rakov V A and Uman M A 2003 Lightning physics and effects (New York: Cambridge University Press), pp. 321-346.

Uman M A 2001 The lightning discharge (Mineola, New York: Dover) 377p.

Uman M A, Cookson A H and Moreland J B 1970 Shock wave from a four-meter spark; J. Appl. Phys. 41 3148-3152.

Zhang J C, Yuan P and Ouyang Y H 2010 Characteristics of absorption and attenuation of thunder propagating in atmosphere; Acta Physica Sinica 59(11) 8287-8292 (in Chinese). 